\title{
Impact of analyzing less image frames per segment for radiofrequency-based volumetric intravascular ultrasound measurements in mild-to-moderate coronary atherosclerosis
}

\author{
Jennifer Huisman • Marc Hartmann • Eline S. K. Mattern • \\ Gary S. Mintz • Mounir W. Z. Basalus • Gert K. van Houwelingen • \\ Patrick M. J. Verhorst • Clemens von Birgelen
}

Received: 11 August 2009/Accepted: 6 February 2010/Published online: 27 February 2010

(C) The Author(s) 2010. This article is published with open access at Springerlink.com

\begin{abstract}
Volumetric radiofrequency-based intravascular ultrasound (RF-IVUS) data of coronary segments are increasingly used as endpoints in serial trials of novel anti-atherosclerotic therapies. In a relatively time-consuming process, vessel and lumen contours are defined; these contours are first automatically detected, then visually checked, and finally (in most cases) manually edited to generate reliable volumetric data of vessel geometry and plaque composition. Reduction in number of cross-sectional images for volumetric analysis could save analysis time but may also increase measurement variability of volumetric data. To assess whether a $50 \%$ reduction in number of frames per segment (every second frame) alters the reproducibility of volumetric
\end{abstract}

J. Huisman · M. Hartmann · E. S. K. Mattern ·

M. W. Z. Basalus · G. K. van Houwelingen ·

P. M. J. Verhorst · C. von Birgelen ( $\triangle)$

Department of Cardiology, Thoraxcentrum Twente,

Medisch Spectrum Twente, Haaksbergerstraat 55,

7513 ER Enschede, The Netherlands

e-mail: c.vonbirgelen@mst.nl

\section{G. S. Mintz}

Cardiovascular Research Foundation, New York, NY, USA

C. von Birgelen

University of Twente, Institute for Biomedical

Technology (BMTI), Enschede, The Netherlands measurements, we performed repeated RF-IVUS analyses of 15 coronary segments with mild-tomoderate atherosclerosis $(20.2 \pm 0.2 \mathrm{~mm}$-long segments with $46 \pm 13 \%$ plaque burden). Volumes were calculated based on a total of 731 image frames. Reducing the number of cross-sectional image frames for volumetric measurements saved analysis time (38 \pm 9 vs. $68 \pm 17 \mathrm{~min} / \mathrm{segment} ; P<0.0001)$ and resulted for only a few parameters in (borderline) significant but mild differences versus measurements based on all frames (fibrous volume, $P<0.05$; necrotic-core volume, $P=0.07)$. Compared to the intra-observer variability, there was a mild increase in measurement variability for most geometrical and compositional volumetric RF-IVUS parameters. In RF-IVUS studies of mild-to-moderate coronary disease, analyzing less image frames saved analysis time, left most volumetric parameters greatly unaffected, and resulted in a no more than mild increase in measurement variability of volumetric data.

Keywords Intravascular ultrasound . Radiofrequency · Virtual histology · Plaque composition - Necrotic core . Vulnerable plaque · IVUS · VH-IVUS · Reproducibility · Variability · Atherosclerosis · Coronary artery disease $\cdot$ Coronary vessels
Abbreviations
IVUS Intravascular ultrasound
RF Radiofrequency 


\section{Introduction}

Volumetric intravascular ultrasound (IVUS) data used in serial studies of coronary atherosclerosis can be obtained from motorized transducer or catheter pullbacks by applying the trapezium method (modification of the Simpson's rule) to cross-sectional area data [1-6]. While most previous IVUS studies assessed vessel geometry using only greyscale IVUS, [3, 7-9] radiofrequency-based IVUS (RF-IVUS) permits measurements of both vessel geometry and plaque composition [10-15]. RF-IVUS systems automatically detect the coronary vessel and lumen boundaries; however, in order to generate reliable volumetric IVUS data, these automaticallydetected contours have to be visually checked and in a majority of cases manually corrected [16-20]. As this is a relatively time-consuming process, theoretically it makes sense to reduce the number of crosssectional IVUS frames (number of frames per $\mathrm{cm}$ ) used for volumetric measurements and thus to be corrected [6]. As recent serial IVUS studies measured only small changes in plaque volume or tissue composition, such reduction in cross-sectional IVUS frames should not have a significant impact on the variability of volumetric RF-IVUS data [18, 21-23].

Therefore, in the present study we evaluated the impact of reducing the number of cross-sectional IVUS image frames used to generate RF-IVUS volumetric data. Our study was performed in coronary segments with mild-to-moderate atherosclerosis in order to reflect the degree of atherosclerosis typically assessed in current progression-regression trials.

\section{Methods}

Study population

We repeatedly analyzed IVUS image sets of $20 \mathrm{~mm}$ long, mild-to-moderately diseased coronary segments from non-target and non-treated coronary arteries with an angiographic lumen diameter stenosis $<50 \%$ and absence of severe calcification or vessel tortuousity. IVUS image sets were obtained from motorized IVUS pullbacks at $0.5 \mathrm{~mm} / \mathrm{s}$ from 15 patients in regular sinus rhythm in whom IVUS was performed during clinically-driven, elective diagnostic cardiac catheterizations $(n=8)$ or percutaneous coronary interventions (of another vessel) $(n=7)$. Informed consent was obtained prior to cardiac catheterization from all patients in accordance with the directives of the Local Medical Ethics Committee.

\section{RF-IVUS and image acquisition}

Details regarding the RF-IVUS technique and validation have previously been described [11-15, 24]. In brief, spectral analysis of IVUS RF-data is used to create tissue maps in order to classify atherosclerotic plaques into four major components (fibrous, fibrolipidic, calcium, and necrotic-core). These four plaque components are represented according to a dedicated colour code (green, light-green, white, and red, respectively).

RF-IVUS data was acquired with commercially available phased-array IVUS catheters (Eagle-Eye ${ }^{\mathrm{TM}}$ $20 \mathrm{MHz}$, Volcano Corporation, Rancho Cordova, CA, USA) by a dedicated RF-IVUS console (InVision Gold ${ }^{\mathrm{TM}}$, Volcano Corporation). Image acquisition was ECG-gated; the catheter probe was advanced $\geq 10 \mathrm{~mm}$ distal to the most distal side-branch. Angiographic cine runs were performed to define the position of the IVUS catheter. After intracoronary injection of $200 \mu \mathrm{g}$ nitroglycerine, a continuous pullback of the IVUS catheter was performed at a speed $0.5 \mathrm{~mm} / \mathrm{s}$. Data were stored on hard disk for off-line analyses.

\section{IVUS image analysis}

The IVUS analysis was performed off-line by an experienced IVUS analyst who recorded the time spent to perform the analysis. The region of interest was a mild-to-moderately diseased atherosclerotic coronary segment $(20 \mathrm{~mm}$ length) located between two adjacent side-branches that contained no major calcification that could have limited quantitative assessment of vessel cross-sectional area.

Vessel and lumen borders were traced using a semi-automated contour detection program (Volcano pcVH software program version 2.2 by Volcano Therapeutics Inc., CA, USA). The automatically detected borders of each cross-sectional image were visually checked and, if required, contours were corrected by computer-assisted manual editing. The vessel border involved tracing the leading edge of the 
adventitia, and the lumen border involved tracing the leading edge of the intima. Plaque + media (vessel minus lumen) was used as a measure of atherosclerotic plaque [4].

For each coronary segment, volumetric data of vessel, lumen, and plaque + media, as well as fibrous, fibro-lipidic, necrotic core, and calcified tissue (absolute and relative amount of the plaque) were generated by application of the trapezium method (modification of the Simpson's rule) to the cross-sectional area measurements [17]. The pcVH software program uses this method that considers the exact spacing between individual image frames to calculate volumes from the cross-sectional area data. Volumetric plaque burden $(\%)$ was calculated as $[$ (plaque + media volume/total vessel volume) $\times 100]$.

IVUS data analysis and rationale

We obtained volumetric IVUS data (geometrical and compositional) from different analyses, each performed on all 15 coronary segments. These different volumetric analyses were performed to obtain insight into the effect of reducing the number of crosssectional image frames per segment on which the volumetric measurements were based. Analyses were spread over a period of 3 months; the analyst was blinded to the results of previous analyses.

Contour detection with manual correction of every cross-sectional image frame was performed to generate volumetric data (Analysis I, Fig. 1). This analysis was then performed a second time (Analysis II, Fig. 1) to assess intra-observer variability.

In addition, following the automated contour detection (always performed by the pcVH software on all frames), the contours of every other frame were skipped (i.e., they were not checked, not corrected, and not used for calculation of volumetric data). Manual contour editing was performed on this reduced number of image frames in order to generate new volumetric data (Analysis III, Fig. 1). In other words: Analysis III was based on contours obtained from less cross-sectional image frames (less data and potentially more difficult contour editing).

In an attempt to assess the mechanism (less data vs. more difficult image analysis) of a potential difference between analysis I and III, we finally recalculated volumes based on the contours of Analysis I, using only the cross-sectional area data of every other frame (i.e., measurements based on less data but without potentially more difficult image analysis). Thus, volumetric data obtained by the latter analysis as well as Analyses III were both based on 50\% of the image frames of the total set of images.

Statistical analysis

Analyses were performed with SPSS 15.0 (SPSS Inc., Chicago, IL, USA). Dichotomous data are presented as frequencies. Quantitative data are presented as mean $\pm 1 \mathrm{SD}$ and compared using student $t$-test. To test the correlation between the different analyses at individual level, the intraclass correlations were calculated. According to Bland and Altman, the agreement between two measurements were assessed by determining the mean $\pm 2 \mathrm{SD}$ of the between measurement differences [25]. A two-sided $P$-value $<0.05$ was considered significant.

\section{Results}

Study population and RF-IVUS data

A total of 15 diffusely diseased, mild-to-moderately atherosclerotic coronary segments (4 RCA, 7 LAD, and 4 LCX) from 15 patients with stable angina (12 men; $60 \pm 8$ years of age) were studied. The heart rate during IVUS examination was $75 \pm 19 / \mathrm{min}$. There were no complications related to IVUS imaging.

A total of 15 coronary segments (731 IVUS frames; $49 \pm 10$ frames/segment) was repeatedly analyzed. Segment length measured $20.2 \pm 0.2 \mathrm{~mm}$ with a volumetric plaque burden of $46 \pm 13 \%$. The atherosclerotic segments contained pre-dominantly fibrous tissue. The number of frames/cm analyzed was $24 \pm 11.5$ for Analyses I and II (all frames) and $12 \pm 2.4$ for Analyses III (reduced number of frames). The mean distance between consecutive frames used for generation of volumetric data was $0.4 \pm 0.1 \mathrm{~mm}$ (range 0.3-0.6) for Analyses I and II and $0.9 \pm 0.2 \mathrm{~mm}$ (range 0.6-1.1) for Analyses III. IVUS data are presented in Table 1.

Time of analysis and measurement variability

Comparing Analysis I to Analysis II showed that there was little intra-observer variability (Table 2) 
Fig. 1 Different ways of RF-data analysis and generation of volumetric data

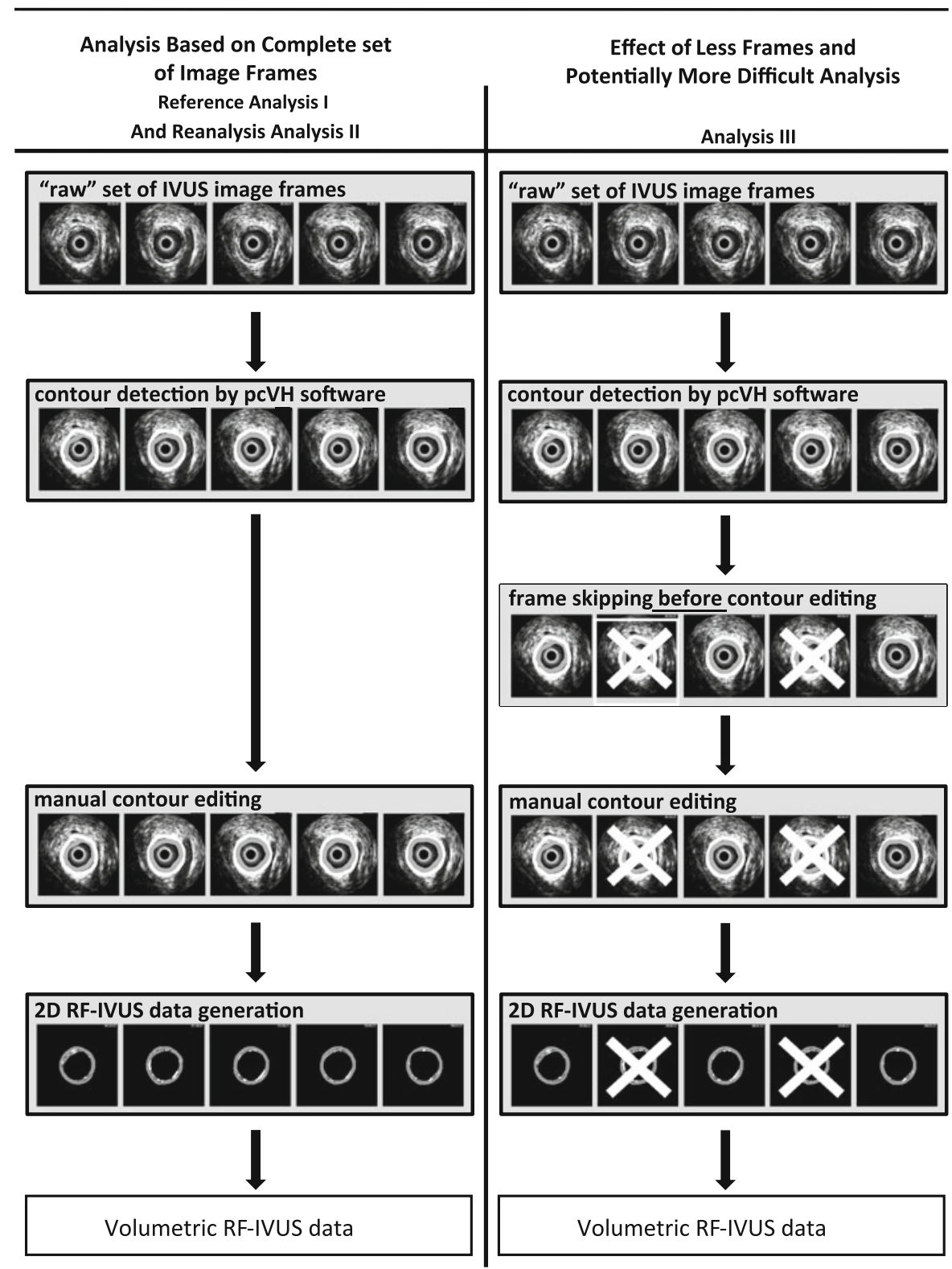

with high intraclass correlations (all $\geq 0.997$ ) and Bland-Altman plots that showed good agreement between measurements (Figs. 2, 3). This was true for both geometric volumes as well as volumes of the four plaque components.

The use of less cross-sectional image frames for the generation of volumetric data (contour editing on less images required; Analysis III) significantly reduced the time of analysis from $68 \pm 17$ to $38 \pm 9$ min $(P<0.0001)$. In addition, it resulted in mild differences versus measurements based on all crosssectional image frames (Analysis I versus Analysis III, Table 2; Figs. 2, 3); differences were only significant for fibrous volume and borderline significant for necrotic-core volume $(P<0.05$ and $P=0.07$, respectively). Intraclass correlations were high (all $\geq 0.992$ ) and Bland-Altman plots showed good agreement. Plaque components, expressed as percentage of plaque, showed no differences $(P \geq 0.1$; data not shown). 
Table 1 IVUS data of four different ways of RF-IVUS analysis

\begin{tabular}{lccc}
\hline & $\begin{array}{l}\text { Analysis I } \\
\text { Reference }\end{array}$ & $\begin{array}{l}\text { Analysis II } \\
\text { Reanalysis based } \\
\text { on complete set } \\
\text { of frames }\end{array}$ & $\begin{array}{l}\text { Analysis III } \\
\text { Less frames } \\
\text { and potentially } \\
\text { more difficult analysis }\end{array}$ \\
\hline $\begin{array}{l}\text { Vessel geometry } \\
\text { Total vessel volume }\left(\mathrm{mm}^{3}\right)\end{array}$ & $344.6 \pm 100.3$ & $344.3 \pm 100.7$ & $345.8 \pm 101.1$ \\
Lumen volume $\left(\mathrm{mm}^{3}\right)$ & $186.0 \pm 72.4$ & $186.9 \pm 72.1$ & $185.0 \pm 73.0$ \\
Plaque + media volume $\left(\mathrm{mm}^{3}\right)$ & $158.6 \pm 61.6$ & $157.4 \pm 62.4$ & $160.8 \pm 65.3$ \\
Plaque burden $(\%)$ & $45.9 \pm 12.9$ & $45.5 \pm 13.0$ & $46.3 \pm 13.6$ \\
Plaque composition & $52.2 \pm 32.5$ & $51.9 \pm 32.4$ & $53.8 \pm 34.5$ \\
Fibrous volume $\left(\mathrm{mm}^{3}\right)$ & $12.7 \pm 11.6$ & $12.7 \pm 11.7$ & $13.3 \pm 12.5$ \\
Fibro-Lipidic volume $\left(\mathrm{mm}^{3}\right)$ & $16.0 \pm 13.5$ & $15.9 \pm 13.5$ & $16.3 \pm 13.7$ \\
Necrotic core volume $\left(\mathrm{mm}^{3}\right)$ & $8.3 \pm 7.1$ & $8.3 \pm 7.1$ & $8.3 \pm 7.1$ \\
Calcium volume $\left(\mathrm{mm}^{3}\right)$ & & & \\
\hline
\end{tabular}

Table 2 Measurement differences of RF-IVUS data derived from different ways of analysis

a Two-sided $t$-test

\begin{tabular}{|c|c|c|}
\hline & \multicolumn{2}{|l|}{ Analysis I versus $^{\mathrm{a}}$} \\
\hline & $\begin{array}{l}\text { Analysis II } \\
\text { Reanalysis based on } \\
\text { complete set of frames }\end{array}$ & $\begin{array}{l}\text { Analysis III } \\
\text { Less frames and potentially } \\
\text { more difficult analysis }\end{array}$ \\
\hline \multicolumn{3}{|l|}{ Vessel geometry } \\
\hline$\Delta$ Total vessel volume $(\mathrm{mm} 3)$ & $\begin{array}{l}0.35 \pm 3.61 \\
P=0.7\end{array}$ & $\begin{array}{l}-1.20 \pm 5.16 \\
P=0.4\end{array}$ \\
\hline$\Delta$ Lumen volume $\left(\mathrm{mm}^{3}\right)$ & $\begin{array}{l}-0.84 \pm 3.87 \\
P=0.4\end{array}$ & $\begin{array}{l}1.01 \pm 4.32 \\
P=0.4\end{array}$ \\
\hline$\Delta$ Plaque + media volume $\left(\mathrm{mm}^{3}\right)$ & $\begin{array}{l}1.19 \pm 3.55 \\
P=0.2\end{array}$ & $\begin{array}{l}-2.20 \pm 6.32 \\
P=0.2\end{array}$ \\
\hline$\Delta$ Plaque burden $(\%)$ & $\begin{array}{l}0.37 \pm 1.00 \\
P=0.2\end{array}$ & $\begin{array}{l}-0.37 \pm 1.38 \\
P=0.3\end{array}$ \\
\hline \multicolumn{3}{|l|}{ Plaque composition } \\
\hline$\Delta$ Fibrous volume $\left(\mathrm{mm}^{3}\right)$ & $\begin{array}{l}0.23 \pm 2.09 \\
P=0.7\end{array}$ & $\begin{array}{l}-1.60 \pm 2.85 \\
P=0.048\end{array}$ \\
\hline$\Delta$ Fibro-lipidic volume $\left(\mathrm{mm}^{3}\right)$ & $\begin{array}{l}-0.02 \pm 0.73 \\
P=0.9\end{array}$ & $\begin{array}{l}-0.60 \pm 1.48 \\
P=0.1\end{array}$ \\
\hline$\Delta$ Necrotic core volume $\left(\mathrm{mm}^{3}\right)$ & $\begin{array}{l}0.05 \pm 0.54 \\
P=0.7\end{array}$ & $\begin{array}{l}-0.36 \pm 0.71 \\
P=0.07\end{array}$ \\
\hline$\Delta$ Calcium volume $\left(\mathrm{mm}^{3}\right)$ & $\begin{array}{l}-0.01 \pm 0.28 \\
P=0.9\end{array}$ & $\begin{array}{l}0.06 \pm 0.48 \\
P=0.6\end{array}$ \\
\hline
\end{tabular}

Between data obtained in Analysis I versus Analysis III, there was a mild increase in measurement variability for most geometrical and compositional volumetric RF-IVUS parameters when being compared to the intra-observer variability (Analysis I versus Analysis II).
Potential mechanism of increased measurement variability

Re-calculation of volumes based on the contours of Analysis I but using only every other frame resulted in volumetric data that did not significantly differ versus 

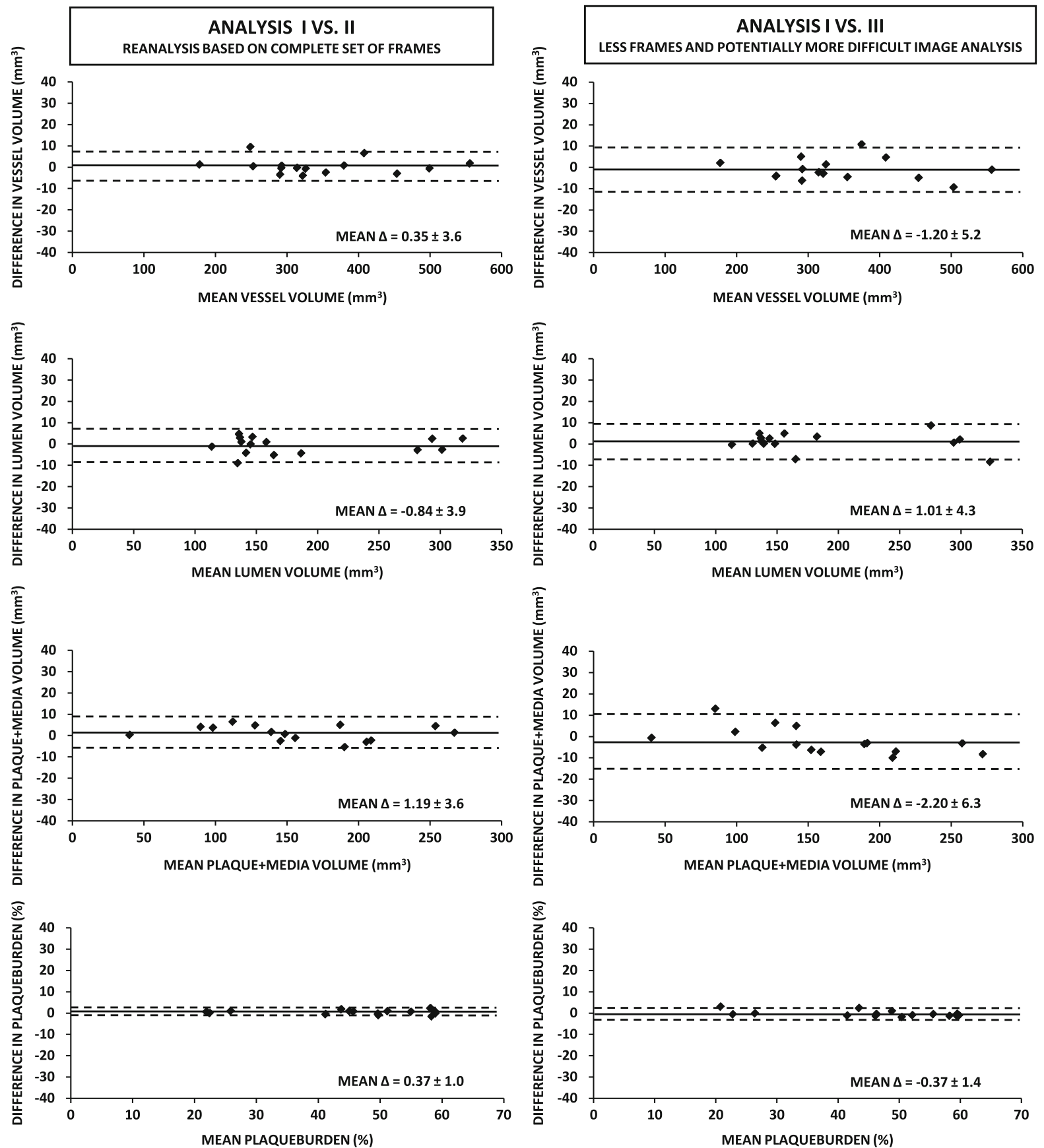

Fig. 2 Bland-Altman comparison of different ways of RF-IVUS analysis for geometrical data

Analyses I $(P=\mathrm{ns})$. Intraclass correlations were high (all $\geq 0.997$ ) and Bland-Altman plots showed good agreement (data not shown). For all volumetric parameters, measurement variability between these two analyses was lower than measurement variability between Analysis I versus Analysis III.

\section{Discussion}

In the present study we evaluated the impact of reducing the number of cross-sectional IVUS image frames on the calculation of RF-IVUS based volumetric data in coronary segments with mild-to- 

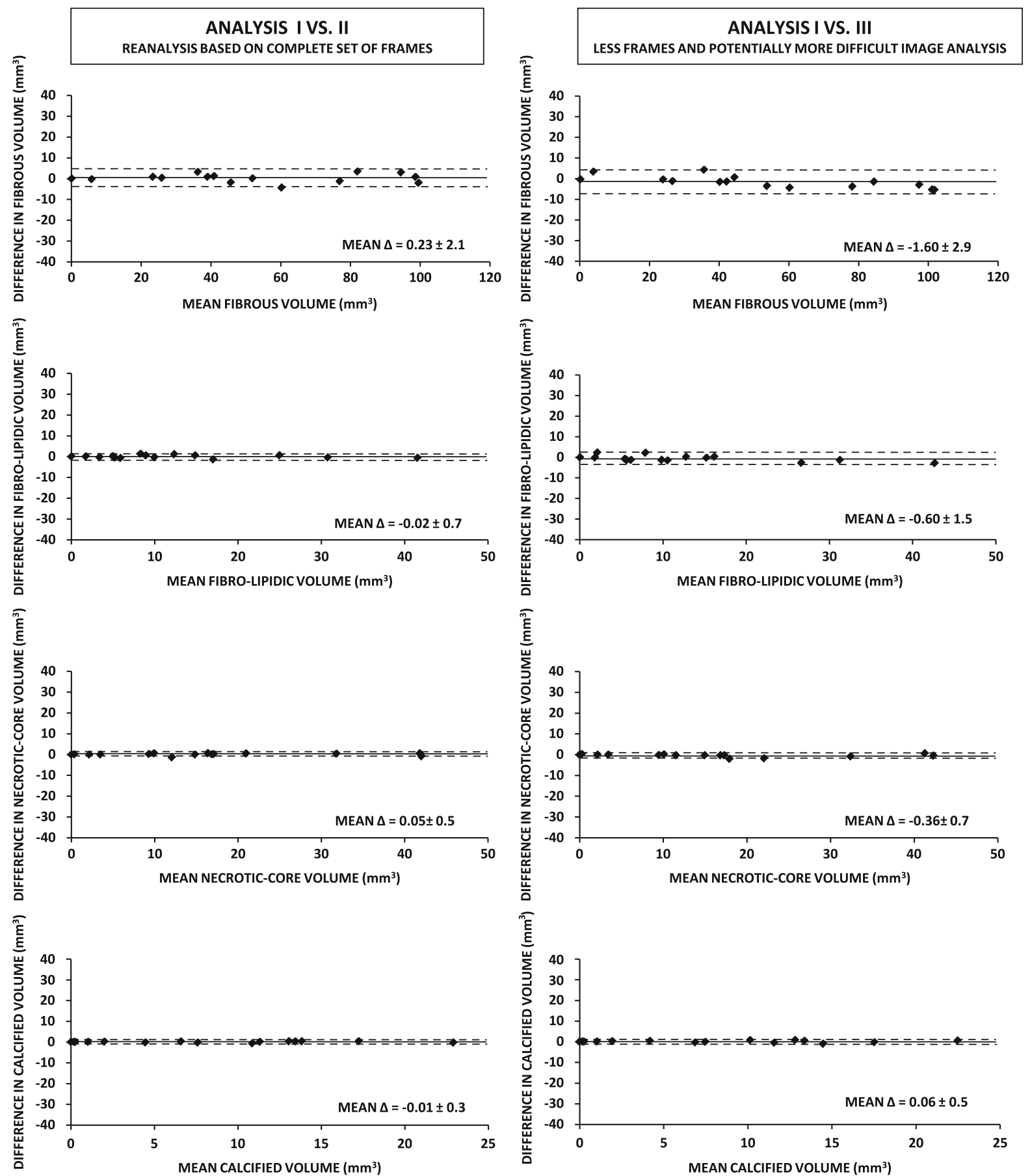

Fig. 3 Bland-Altman comparison of different ways of RF-IVUS analysis for compositional data

moderate atherosclerosis. Reducing the number of cross-sectional image frames for volumetric measurements (=Analysis III) significantly saved analysis time and resulted for only a few parameters in (borderline) significant but mild differences versus measurements based on all frames. In general, observed differences were higher than the intraobserver variability. This increase in measurement 
variability appears to be the result of a somewhat more difficult image analysis (Analysis III, contour editing on a reduced number of image frames and less data), as the generation of volumes from $50 \%$ of the already contour-edited images of Analysis I (only less data) showed a lower measurement variability.

\section{Reproducibility of RF-IVUS}

An important pre-requisite for the meaningful interpretation of data obtained by RF-IVUS is the assessment of measurement reproducibility $[12,16$, 26, 27]. Rodriguez-Granillo et al. [27] tested the measurement variability of two-dimensional RFIVUS data obtained from 16 coronary atherosclerotic lesions. The relative intra-observer difference was $\leq 3 \%$ for geometric cross-sectional area measurements; conversely, compositional measurements were more variable than geometric measurements and, on average, varied by up to $13 \%$ on repeated pullbacks [27]. Prasad et al. [26] reported that RF-IVUS measurements of plaque composition volumes in 12 coronary segments $(11 \pm 4 \mathrm{~mm})$ had a high measurement reproducibility (on average $\leq 6 \%$ ). Our own group found in 33 coronary segments $(27 \pm 7 \mathrm{~mm})$ a relatively high measurement reproducibility of volumetric RF-IVUS composition analyses (on average $\leq 3 \%$ ) [16]. However, volumetric RF-IVUS analyses are very time consuming due to the contour detection and manual correction of most image frames per segment [16]. As demonstrated in the current study, reduction of the number of image frames used for the generation of volumetric measurements is time sparing, but resulted in a mild increase in measurement variability for most geometrical and compositional volumetric RF-IVUS parameters; there were only for a few parameters (borderline) significant but mild differences versus measurements based on all frames. Of the four plaque components, calcified tissue showed the lowest measurement variability. In general, differences in plaque composition may be the result of small variations in vessel and lumen border detection and/ or differences in the interpolation of the vessel and lumen contour at the site of side branches. As calcified tissue was more often located centrally in the plaque, this tissue component may be less dependent on editing of the vessel and lumen contours.
Changes observed in serial IVUS studies and implications of this study

Serial volumetric IVUS data are increasingly used as endpoints in pharmacological intervention trials as changes in IVUS plaque dimensions may be linked to a significant increase or decrease in risk of clinical events [1, 8, 18, 23]. Besides coronary plaque progression/regression, changes in atherosclerotic plaque composition may also alter the risk of cardiovascular events [28-30]. RF-IVUS discriminates between plaque vulnerability versus plaque stability (necrotic core vs. fibrous tissue) [11, 12, 14, 20, 31]. Therefore, RF-IVUS is increasingly used in studies that evaluate plaque stabilization during pharmacological interventions with novel atherosclerosis-modifying drugs [18, 21-23]. Necrotic core and fibro-lipidic tissue are both markers of plaque vulnerability and may be more interesting imaging endpoints than fibrous tissue which is a marker of plaque stability. Fibrous tissue is often located adjacent to the lumen border and variation in editing the lumen contour may result in misinterpretation of blood as fibrous (and sometimes fibro-lipidic) tissue [32]. This may result in an increased variability of fibrous and fibro-lipidic tissue measurements (in the present study $>5$ and $>11 \%$, respectively). Importantly, a relatively low measurement variability for necrotic core $(<5 \%$ in the present study) is a prerequisite for use of this imaging parameter as an endpoint of pharmacological intervention trials.

The recently published data of IBIS-2 (Integrated Biomarker and Imaging Study II) reported changes in volumetric RF-IVUS data during 12 months of treatment with the lipoprotein-associated phospholipaseA2 inhibitor darapladib versus placebo [23]. In the placebo-group, necrotic core volume increased by $4.5 \pm 17.9 \mathrm{~mm}^{3}(P=0.009)$ whereas patients on darapladib showed no increase in necrotic core volume with no significant change in plaque volume or plaque burden. The relatively small changes in overall plaque volume and the volume of each plaque component that have been reported in these aforementioned serial studies suggest that measurement reproducibility is critical [12, 16, 17, 26, 27]. The present study showed that saving time of analysis by reducing the number of cross-sectional images used for volumetric data and thus analyzed $(24 \pm 11.5$ vs. $12 \pm 2.4$ frames $/ \mathrm{cm})$ is offset by a significant but mild increase in 
measurement variability that is higher than the level of the intra-observer measurement variability. Consequently, RF-IVUS studies of mild-to-moderate coronary atherosclerosis should ideally analyze all image frames of the coronary segments in order to minimize measurement variability; however, it could be considered (partly related to the parameters of interest) whether all frames or a reduced number of frames should be used.

\section{Limitations}

The number of coronary segments studied $(n=15)$ was limited. Other studies that addressed the reproducibility of VH-IVUS measurements examined series of $n=16-33$ coronary segments [16, 26, 27]. Recent pharmacological intervention trials with IVUS endpoints examined 10-40 mm-long coronary segments and $10 \mathrm{~mm}$-long subsegments with the greatest disease burden $[8,21,22]$. The segment length of the present study $(20.2 \pm 0.2 \mathrm{~mm})$ reflects this choice and is in accordance with recent recommendations of an expert panel [10]. All patients had stable angina. Similar to other studies with IVUS and RF-IVUS, we excluded tortuous and severely calcified vessels that could have hampered the uniform pullback speed and IVUS image interpretation [16, 18, 23, 26, 27]. In addition, extensive circumferential calcified tissue may limit the detection of vessel contours, which is a known limitation of IVUS. In this study, we analyzed IVUS image runs with limited circumferential calcification, which may have facilitated vessel contour detection to some extent; measurement reproducibility could be somewhat lower in cases with extensive calcification. The data of this study do not predict whether a reduction of image density may introduce an additional measurement variability (for instance when data are sampled at a pullback speed of $1.0 \mathrm{~mm} / \mathrm{s}$ instead of $0.5 \mathrm{~mm} / \mathrm{s}$ ). In serial studies, [33] potential variability between different IVUS catheters or IVUS systems may add to the overall measurement variability of RF-IVUS studies [34].

\section{Conclusions}

Analyzing less cross-sectional image frames saved analysis time on the generation of volumetric RF-IVUS data in mild-to-moderate coronary disease, left most volumetric parameters greatly unaffected, and resulted in a no more than mild increase in measurement variability of volumetric data.

Open Access This article is distributed under the terms of the Creative Commons Attribution Noncommercial License which permits any noncommercial use, distribution, and reproduction in any medium, provided the original author(s) and source are credited.

\section{References}

1. Böse D, von Birgelen C, Erbel R (2007) Intravascular ultrasound for the evaluation of therapies targeting coronary atherosclerosis. J Am Coll Cardiol 49(9):925-932

2. Bruining N, von Birgelen C, de Feyter PJ, Ligthart J, Li W, Serruys PW, Roelandt JR (1998) ECG-gated versus nongated three-dimensional intracoronary ultrasound analysis: implications for volumetric measurements. Cathet Cardiovasc Diagn 43(3):254-260

3. Jensen LO, Thayssen P (2007) Accuracy of electrocardiographic-gated versus nongated volumetric intravascular ultrasound measurements of coronary arterial narrowing. Am J Cardiol 99(2):279-283

4. Mintz GS, Nissen SE, Anderson WD, Bailey SR, Erbel R, Fitzgerald PJ, Pinto FJ, Rosenfield K, Siegel RJ, Tuzcu EM, Yock PG (2001) American college of cardiology clinical expert consensus document on standards for acquisition, measurement and reporting of intravascular ultrasound studies (IVUS). A report of the American college of cardiology task force on clinical expert consensus documents. J Am Coll Cardiol 37(5):1478-1492

5. von Birgelen C, de Vrey EA, Mintz GS, Nicosia A, Bruining N, Li W, Slager CJ, Roelandt JR, Serruys PW, de Feyter PJ (1997) ECG-gated three-dimensional intravascular ultrasound: feasibility and reproducibility of the automated analysis of coronary lumen and atherosclerotic plaque dimensions in humans. Circulation 96(9): 2944-2952

6. von Birgelen C, de Feyter PJ, de Vrey EA, Li W, Bruining N, Nicosia A, Roelandt JR, Serruys PW (1997) Simpson's rule for the volumetric ultrasound assessment of atherosclerotic coronary arteries: a study with ECG-gated threedimensional intravascular ultrasound. Coron Artery Dis 8(6):363-369

7. Jensen LO, Thayssen P, Pedersen KE, Stender S, Haghfelt $\mathrm{T}$ (2004) Regression of coronary atherosclerosis by simvastatin: a serial intravascular ultrasound study. Circulation 110(3):265-270

8. Nissen SE, Nicholls SJ, Sipahi I, Libby P, Raichlen JS, Ballantyne CM, Davignon J, Erbel R, Fruchart JC, Tardif JC, Schoenhagen P, Crowe T, Cain V, Wolski K, Goormastic M, Tuzcu EM (2006) Effect of very high-intensity statin therapy on regression of coronary atherosclerosis: the ASTEROID trial. JAMA 295(13):1556-1565

9. Schartl M, Bocksch W, Koschyk DH, Voelker W, Karsch KR, Kreuzer J, Hausmann D, Beckmann S, Gross M (2001) Use of intravascular ultrasound to compare effects 
of different strategies of lipid-lowering therapy on plaque volume and composition in patients with coronary artery disease. Circulation 104(4):387-392

10. Garcia-Garcia HM, Mintz GS, Lerman A, Vince DG, Margolis P, van Es GA, Morel MA, Nair A, Virmani R, Burke AP, Stone GW, Serruys PW (2009) Tissue characterisation using intravascular radiofrequency data analysis: recommendations for acquisition, analysis, interpretation and reporting. EuroIntervention 5(2):177-189

11. Konig A, Klauss V (2007) Virtual histology. Heart 93(8):977-982

12. Mehta SK, McCrary JR, Frutkin AD, Dolla WJ, Marso SP (2007) Intravascular ultrasound radiofrequency analysis of coronary atherosclerosis: an emerging technology for the assessment of vulnerable plaque. Eur Heart J 28(11): $1283-1288$

13. Nair A, Margolis MP, Kuban BD, Vince DG (2007) Automated coronary plaque characterisation with intravascular ultrasound backscatter: ex vitro validation. EuroIntervention 3(1):113-120

14. Nair A, Kuban BD, Tuzcu EM, Schoenhagen P, Nissen SE, Vince DG (2002) Coronary plaque classification with intravascular ultrasound radiofrequency data analysis. Circulation 106(17):2200-2206

15. Nasu K, Tsuchikane E, Katoh O, Vince DG, Virmani R, Surmely JF, Murata A, Takeda Y, Ito T, Ehara M, Matsubara T, Terashima M, Suzuki T (2006) Accuracy of in vivo coronary plaque morphology assessment: a validation study of in vivo virtual histology compared with in vitro histopathology. J Am Coll Cardiol 47(12):2405-2412

16. Hartmann M, Mattern ES, Huisman J, van Houwelingen GK, de Man FH, Stoel MG, Danse PW, Louwerenburg HW, von Birgelen C (2009) Reproducibility of volumetric intravascular ultrasound radiofrequency-based analysis of coronary plaque composition in vivo. Int $\mathrm{J}$ Cardiovasc Imaging 25(1):13-23

17. Huisman J, Egede R, Rdzanek A, Böse D, Erbel R, Kochman J, Jensen LO, van de Palen J, Hartmann M, Mintz GS, and von Birgelen C (2009) Between-centre reproducibility of volumetric intravascular ultrasound radiofrequency-based analyses in mild-to-moderate coronary atherosclerosis: an international multicentre study. EuroIntervention (in press)

18. Kawasaki M, Sano K, Okubo M, Yokoyama H, Ito Y, Murata I, Tsuchiya K, Minatoguchi S, Zhou X, Fujita H, Fujiwara H (2005) Volumetric quantitative analysis of tissue characteristics of coronary plaques after statin therapy using three-dimensional integrated backscatter intravascular ultrasound. J Am Coll Cardiol 45(12):1946-1953

19. Missel E, Mintz GS, Carlier SG, Qian J, Shan S, Castellanos C, Kaple R, Biro S, Fahy M, Moses JW, Stone GW, Leon MB (2008) In vivo virtual histology intravascular ultrasound correlates of risk factors for sudden coronary death in men: results from the prospective, multi-centre virtual histology intravascular ultrasound registry. Eur Heart J 29(17):2141-2147

20. Rodriguez-Granillo GA, Garcia-Garcia HM, Mc Fadden EP, Valgimigli M, Aoki J, de Feyter PJ, Serruys PW (2005) In vivo intravascular ultrasound-derived thin-cap fibroatheroma detection using ultrasound radiofrequency data analysis. J Am Coll Cardiol 46(11):2038-2042
21. Hong MK, Park DW, Lee CW, Lee SW, Kim YH, Kang DH, Song JK, Kim JJ, Park SW, Park SJ (2009) Effects of statin treatments on coronary plaques assessed by volumetric virtual histology intravascular ultrasound analysis. JACC Cardiovasc Interv 2(7):679-688

22. Nasu K, Tsuchikane E, Katoh O, Tanaka N, Kimura M, Ehara M, Kinoshita Y, Matsubara T, Matsuo H, Asakura K, Asakura Y, Terashima M, Takayama T, Honye J, Hirayama A, Saito S, Suzuki T (2009) Effect of fluvastatin on progression of coronary atherosclerotic plaque evaluated by virtual histology intravascular ultrasound. JACC Cardiovasc Interv 2(7):689-696

23. Serruys PW, Garcia-Garcia HM, Buszman P, Erne P, Verheye S, Aschermann M, Duckers H, Bleie O, Dudek D, Botker HE, von Birgelen C, D'Amico D, Hutchinson T, Zambanini A, Mastik F, van Es GA, van der Steen AF, Vince DG, Ganz P, Hamm CW, Wijns W, Zalewski A (2008) Effects of the direct lipoprotein-associated phospholipase $\mathrm{A}(2)$ inhibitor darapladib on human coronary atherosclerotic plaque. Circulation 118(11):1172-1182

24. Dijkstra J, Koning G, Reiber JH (1999) Quantitative measurements in IVUS images. Int $\mathbf{J}$ Card Imaging 15(6):513-522

25. Bland JM, Altman DG (1986) Statistical methods for assessing agreement between two methods of clinical measurement. Lancet 1(8476):307-310

26. Prasad A, Cipher DJ, Prasad A, Mohandas A, Roesle M, Brilakis ES, Banerjee S (2008) Reproducibility of intravascular ultrasound virtual histology analysis. Cardiovasc Revasc Med 9(2):71-77

27. Rodriguez-Granillo GA, Vaina S, Garcia-Garcia HM, Valgimigli M, Duckers E, van Geuns RJ, Regar E, van der Giessen WJ, Bressers M, Goedhart D, Morel MA, de Feyter PJ, Serruys PW (2006) Reproducibility of intravascular ultrasound radiofrequency data analysis: implications for the design of longitudinal studies. Int $\mathbf{J}$ Cardiovasc Imaging 22(5):621-631

28. Ambrose JA, Tannenbaum MA, Alexopoulos D, Hjemdahl-Monsen CE, Leavy J, Weiss M, Borrico S, Gorlin R, Fuster V (1988) Angiographic progression of coronary artery disease and the development of myocardial infarction. J Am Coll Cardiol 12(1):56-62

29. Burke AP, Farb A, Malcom GT, Liang YH, Smialek J, Virmani R (1997) Coronary risk factors and plaque morphology in men with coronary disease who died suddenly. N Engl J Med 336(18):1276-1282

30. Virmani R, Burke AP, Farb A, Kolodgie FD (2006) Pathology of the vulnerable plaque. J Am Coll Cardiol 47(8 Suppl):C13-C18

31. Hong MK, Mintz GS, Lee CW, Lee JW, Park JH, Park DW, Lee SW, Kim YH, Cheong SS, Kim JJ, Park SW, Park SJ (2008) A three-vessel virtual histology intravascular ultrasound analysis of frequency and distribution of thin-cap fibroatheromas in patients with acute coronary syndrome or stable angina pectoris. Am J Cardiol 101(5):568-572

32. Frutkin AD, Mehta SK, McCrary JR, Marso SP (2007) Limitations to the use of virtual histology-intravascular ultrasound to detect vulnerable plaque. Eur Heart J 28(14):1783-1784

33. Hartmann M, Huisman J, Böse D, Jensen LO, Schoenhagen P, Mintz GS, Erbel R, and von Birgelen C (2009) 
Serial intravascular ultrasound assessment of changes in coronary atherosclerotic plaque dimensions and composition: an update. Eur J Echocardiogr (in press)

34. Hartmann M, von Birgelen C, Mintz GS, Deppermann N, Dirsch O, Stoel MG, van Houwelingen GK, Louwerenburg
HW, Verhorst PM, Erbel R (2006) Dedicated calibration formulas permit correction of differences between measurements by different IVUS devices as demonstrated in atherosclerotic human coronary arteries in vitro. Int $\mathbf{J}$ Cardiovasc Imaging 22(5):605-613 